\title{
The Role of p27Kip1 in the Regulation of Growth Plate Chondrocyte Proliferation in Mice
}

\author{
JOYCE A.M. EMONS, ROSE MARINO, OLA NILSSON, KEVIN M. BARNES, NAOMI EVEN-ZOHAR, ANENISIA C. ANDRADE, \\ NEAL A. CHATTERJEE, JAN M. WIT, MARCEL KARPERIEN, AND JEFFREY BARON
}

\begin{abstract}
Developmental Endocrinology Branch [J.A.M.E., R.M., O.N., K.M.B., N.E.-Z., A.C.A., N.A.C., J.B.], National Institute of Child Health and Human Development, National Institutes of Health, Bethesda, Maryland 20892; Department of Pediatrics [J.A.M.E., J.M.W., M.K.], Department of Endocrinology and Metabolic Diseases [M.K.], Leiden University Medical Center, 2300 WB Leiden, The Netherlands
\end{abstract}

\begin{abstract}
Kip1, a cyclin-dependent kinase inhibitor, negatively regulates proliferation of multiple cell types. The goal of this study was to assess the role of p27 in the spatial, temporal, and conditional regulation of growth plate chondrocyte proliferation. p27 mRNA expression was detected by real-time RT-PCR in all zones of the mouse growth plate at levels approximately 2 -fold lower than in the surrounding bone. To determine whether this expression is physiologically important, we studied skeletal growth in 7-wk-old mice lacking a functional p27 gene. In these mice, body length was modestly increased and proliferation of proximal tibial growth plate chondrocytes was increased, but tibia length was not significantly greater than in controls. p27 ablation had no measurable effect on growth plate morphology. Treatment with dexamethasone inhibited longitudinal bone growth similarly in p27-deficient mice and controls, indicating that $\mathrm{p} 27$ is not required for the inhibitory effects of glucocorticoids on longitudinal growth. p27-deficient mice had increased width of the femoral diaphysis, suggesting that p27 acts normally to inhibit periosteal bone growth. In conclusion, our findings suggest that p27 has modest inhibitory effects on growth plate chondrocyte proliferation but is not required for the spatial or temporal regulation of proliferation or the conditional regulation by glucocorticoid. (Pediatr Res 60: 288-293, 2006)
\end{abstract}

$\mathrm{L}$ ongitudinal bone growth occurs at the growth plate, a thin layer of cartilage located between the epiphysis and the metaphysis, at the ends of the long bones. Bone elongation occurs by a process called endochondral ossification, in which chondrocytes undergo the sequential steps of proliferation, hypertrophic differentiation, and apoptosis. The chondrocytes and the surrounding cartilage matrix are then replaced by bone tissue.

This process of longitudinal bone growth requires precise regulation of chondrocyte proliferation. First, chondrocyte proliferation is regulated spatially within the growth plate; the proliferation rate varies with distance along the long axis of the bone. In the resting and uppermost proliferative zone,

Received March 23, 2006; accepted April 7, 2006.

Correspondence: Joyce A.M. Emons, M.D., Willem-Alexander Kinder-en Jeugdcentrum, Postzone J6-S, PO Box 9600, 2300 RG, Leiden, The Netherlands; e-mail: j.emons@lumc.nl

This study is supported by the Intramural Research Program of the National Institute of Child Health and Human Development, National Institutes of Health, and the Ter Meulen Foundation, The Netherlands.

J.B. is a commissioned officer in the U.S. Public Health Service.

DOI: 10.1203/01.pdr.0000232790.53527.c6 proliferation is slow. Proliferation increases in the midproliferative zone and then slows again in the lower proliferative zone and finally ceases in the hypertrophic zone (1). Second, chondrocyte proliferation varies temporally; the proliferation rate of chondrocytes declines with increasing age (2-5), causing longitudinal bone growth to slow and eventually stop. Third, chondrocyte proliferation is regulated conditionally, in response to conditions elsewhere in the body (1). Some of the extracellular signaling mechanisms that regulate proliferation are known. For example, spatial regulation involves PTH-related protein (PTHrP) and Indian hedgehog (Ihh) and conditional regulation involves circulating IGF-1 and glucocorticoids $(6,7)$. However, the final portion of the pathway is not understood, that is, how the cell cycle of chondrocytes is modulated temporally, spatially, and conditionally.

One of the suggested mechanisms is through orderly activation and inactivation of cyclin-dependent kinases and cyclin-dependent kinase inhibitors that control the cell cycle. Progression of the cell cycle is promoted by activation of cyclin-dependent kinases. Cyclin-dependent kinase inhibitors play important roles in maintaining growth arrest and cell differentiation by binding and inactivating these cyclindependent kinases. In mammals, two known families of cyclin-dependent kinase inhibitors have been identified, INK4 and Cip/Kip. The Cip/Kip family includes p21, p27, and p57, which can act on most cyclin/cyclin-dependent kinase complexes and also on some kinases unrelated to cyclin-dependent kinases, essential for G1 progression and S1 entry (8). Different Cip/Kip inhibitors appear to mediate the growth-inhibiting effects of different stimuli. For example, p21 and p57 expression is increased in cells containing damaged DNA, and p21 expression is also increased in terminally differentiated cells (9). p27 expression, on the other hand, increases in response to extracellular antiproliferative signals, whereas proliferative signals repress p27 expression (10). Cells grown in the presence of antiproliferative factors, like cAMP or rapamycin, have elevated levels of p27 mRNA $(11,12)$.

Previous studies suggest that $\mathrm{p} 27$ may regulate growth plate chondrocyte proliferation and differentiation $(13,14)$. p27 has been detected immunohistochemically in hypertrophic chondrocytes in fetal and early postnatal mice $(15,16)$. p27 has also been detected in cultured rat resting zone chondrocytes where its expression is up-regulated during thyroid hormone-induced 
terminal differentiation (13). Targeted disruption of p27 in mice causes multiorgan hyperplasia and increased body weight, with all tissues proportionally enlarged and containing more cells (14,17-19). Kiyokawa et al. (17) reported an increased size and width of tibiae and femora in p27-deficient mice compared with wild-type mice. However, beyond this, little is known about the role of p27 in regulating skeletal growth.

The current study was designed to explore the role of p27 in the spatial, temporal, and conditional regulation of growth plate chondrocyte proliferation. First, we measured p27 expression in the mouse growth plate using real-time PCR. Second, we assessed growth plate structure, chondrocyte proliferation, longitudinal bone growth, and cortical width in p27-deficient mice. Third, we determined whether p27 mediates the effects of a hormonal modulator of longitudinal bone growth by administering a glucocorticoid to p27-deficient mice.

\section{MATERIALS AND METHODS}

Animals. Heterozygous $\mathrm{p} 27^{+/-}$mice from a mixed C57BL/6J and 129 background were provided by Dr. Jack Pledger (H. Lee Moffitt Cancer Center, University of South Florida College of Medicine, Tampa, FL). These mice were originally generated by Matthew Fero and colleagues (10). The mice were bred in our animal facility to obtain $\mathrm{p} 27^{-/-}$and $\mathrm{p} 27^{+/+}$mice. Mouse colonies were maintained in a pathogen-free environment and fed standard rodent chow (Zeigler Bros, Gardners, PA) with water ad libitum. Animal care was in accordance with the Guide for the Care and Use of Laboratory Animals (National Research Council, 1996). The protocol was approved by the Animal Care and Use Committee, National Institutes of Child and Human Development, National Institutes of Health.

Mouse genotyping. At $3 \mathrm{wk}$ of age, $5 \mathrm{~mm}$ of the tail end was excised under local anesthesia, and genomic DNA was extracted using the DNeasy Tissue Kit (QIAGEN, Valencia, CA). Genotypes were analyzed by PCR. p27 deletions were confirmed by the presence of a $600 \mathrm{bp}$ fragment unique to the mutant genotype amplified with primer $p 27 \mathrm{KO} 1$ (CCT TCT ATG GCC TTC TTG ACG) and primer P27 KO2 (TGG AAC CCT GTG CCA TCT CTA T) (sequences provided by Matthew Fero, Fred Hutchinson Cancer Research Center, Seattle, WA). The PCR reaction mixture (Invitrogen, Carlsbad, CA) contained 5\% DMSO. PCR reactions were performed under the following conditions: $94^{\circ} \mathrm{C}$ for $3 \mathrm{~min}$, followed by 40 cycles of $94^{\circ} \mathrm{C}$ for $1 \mathrm{~min}, 61^{\circ} \mathrm{C}$ for $45 \mathrm{~s}$, and $72^{\circ} \mathrm{C}$ for $45 \mathrm{~s}$, and ending with primer extension at $72^{\circ} \mathrm{C}$ for 5 min. Wild-type alleles were confirmed by the presence of a 190 base-pair fragment amplified with the primers $p 27$ WT1 (GAT GGA CGC CAG ACA AGC) and $p 27$ WT2 (CTC CTG CCA TTC GTA TCT GC) (Dr. Jack Pledger, H. Lee Moffitt Cancer Center, University of South Florida College of Medicine, Tampa, FL, personal communication). The DNA was amplified with PCR conditions as follows: $94^{\circ} \mathrm{C}$ for $3 \mathrm{~min}$, followed by 12 cycles of $94^{\circ} \mathrm{C}$ for $20 \mathrm{~s}, 64^{\circ} \mathrm{C}$ for $30 \mathrm{~s}$ (subtracting $0.5^{\circ} \mathrm{C}$ every cycle) and $72^{\circ} \mathrm{C}$ for $35^{\circ} \mathrm{C}$, followed by 25 cycles of $94^{\circ} \mathrm{C}$ for $20 \mathrm{~s}, 58^{\circ} \mathrm{C}$ for $30 \mathrm{~s}$, and $72^{\circ} \mathrm{C}$ for $35 \mathrm{~s}$, and ending with $72^{\circ} \mathrm{C}$ for $2 \mathrm{~min}$.

Animal procedures and tissue processing. To assess p27 expression in growth plate, five 5-wk-old wild-type C57BL/6J mice and two 5-wk-old mice homozygous for $\mathrm{p} 27$ deletion were sacrificed by cervical dislocation. Proximal tibial growth plates were rapidly excised, embedded in OCT compound (Electron Microscopy Sciences, Hatfield, PA) and stored at $-80^{\circ} \mathrm{C}$ for subsequent processing.

To analyze the skeletal phenotype of p27 deficiency, mice were separated in four groups by their genotypes and sex: $\mathrm{p} 27^{+/+}$female $(n=9), \mathrm{p} 27^{+/+}$ male $(n=10), \mathrm{p} 27^{-1-}$ female $(n=9), \mathrm{p} 27^{-l-}$ male $(n=10)$. At 7 wk of age, mice were killed by inhalation of carbon dioxide. Seven weeks was chosen because previous studies $(17,20)$ demonstrated a significant difference in weight between wild-type and p27-deficient mice beginning at this age. Furthermore, at $7 \mathrm{wk}$ of age, mouse growth plates are still active. Before sacrifice, $200 \mu \mathrm{L}$ 5-bromo-2'-deoxyuridine (BrdU, $10 \mathrm{mg} / \mathrm{mL}$, Sigma Chemical Co-Aldrich, St. Louis, MO) was administered ip at $7 \mathrm{~h}$ and $2 \mathrm{~h}$. The animals were weighed, and body length (nose-base of tail and total length including tail) was determined (21). Heart, liver, spleen, and kidney were excised and weighed. Tibiae and femora were excised, separated from adja- cent muscle, and their lengths were measured using a digital vernier caliper. The left femora were fixed overnight in 10\% phosphate-buffered formalin and preserved in $70 \%$ alcohol for microcomputed tomography. The left tibiae were prepared for histologic analysis by fixing overnight in 10\% phosphatebuffered formalin, decalcifying in 10\% EDTA, and embedding in paraffin.

To assess the effect of dexamethasone in the absence of p27, 3-wk-old mice were divided into a p $27^{+/+}(7$ males, 10 females $)$ and a p $27^{-1-}$ group $(6$ males, 5 females). The animals were all injected subcutaneously with $20 \mu \mathrm{g}$ dexamethasone once a day, five times a week for $4 \mathrm{wk}$. Body weight and body length was measured weekly. BrdU was administered as before. After sacrifice, tibiae and femora were excised and measured. Measurements were compared with nontreated controls.

Isolation and reverse transcription of RNA. Frozen longitudinal sections $(40 \mu \mathrm{m})$ of proximal tibial growth plates from 5-wk-old mice were mounted on Superfrost Plus slides (Histoserv, Germantown, MD). Slides were thawed 2 min, fixed in $70 \%$ ethanol and 95\% ethanol, stained in eosin, washed in $100 \%$ ethanol, and dehydrated in xylene (each step for $60 \mathrm{~s}$, at room temperature). Standard precautions against RNases were used. Using an inverted microscope and a scalpel, from each section, four different zones were separated: epiphyseal bone, resting plus proliferative zone, hypertrophic zone, and metaphyseal bone. To avoid cross-contamination between the resting/proliferative zone and the hypertrophic zone, the boundary segment of cartilage containing the lower proliferative zone and the upper hypertrophic zone was discarded. For each zone, approximately 16 sections from a single animal were pooled before RNA isolation. RNA isolation was performed as previously described except that we scaled down the procedure to use one fifth of each volume and omitted the final precipitation with $\mathrm{LiCl}$ (22). RNA concentration was assessed and integrity was confirmed using a Bioanalyzer 2100, RNA Pico Chips, and version A.02.12 of the Bio Sizing software according to manufacturer's instructions (Agilent Biotechnologies, Inc., Palo Alto, CA).

Reverse transcription was accomplished for the entire RNA solution generated, using the SuperScript III RTS First-Strand cDNA Synthesis Kit from Invitrogen.

Real-time RT-PCR. Expression of p27 mRNA was quantified by real-time quantitative PCR using the ABI Prism 7300 Sequence Detection System (Applied Biosystems, Foster City, CA) with specific, FAM-labeled probes. The oligonucleotide primers and probes for p $27 \mathrm{mRNA}$ and $18 \mathrm{~S}$ ribosomal RNA were supplied by Applied Biosystems; assays 4319413E and Mm00438168_m1, respectively. PCR reactions were performed with the cDNA solution, TaqMan Universal PCR Master Mix, p27 or 18S primers and probes (Applied Biosystems), according to the manufacturer's instructions, using the following thermal cycling conditions: one cycle at $50^{\circ} \mathrm{C}$ for $2 \mathrm{~min}$ and $95^{\circ} \mathrm{C}$ for $10 \mathrm{~min}$, followed by 40 cycles of $15 \mathrm{~s}$ at $95^{\circ} \mathrm{C}$ and $1 \mathrm{~min}$ at $60^{\circ} \mathrm{C}$. Each sample, which represents a single region from a single animal, was assayed in triplicate. The efficiencies of the p27 and 18S PCR reactions were determined using serial dilutions of whole growth plate cDNA.

Quantitative histology. Longitudinal $5 \mu \mathrm{m}$ sections of the proximal tibial growth plate were obtained near the center of the formalin-fixed, decalcified bone, mounted on Superfrost Plus slides (Histoserv) and stained with Masson Trichrome. All histologic measurements were performed in the central two thirds of the growth plate sections. Height was measured at three points parallel to the chondrocyte columns, and results were averaged. The number of proliferative and hypertrophic cells was counted in 15 intact columns per growth plate, and counts were averaged. The terminal hypertrophic chondrocyte was defined as the cell in the last lacuna that was not invaded by metaphyseal blood vessels (5). Heights of 10 lacunae per animal were measured and results were averaged. We only measured lacunae with a sharp boundary, which indicates that the lacunar wall is perpendicular to the plane of section and thus the section had been made near the center of the lacuna.

BrdU labeling and detection. In tissues sections from animals injected with BrdU, labeled cells were visualized with a commercial kit (BrdU staining kit, Zymed, San Francisco, CA), using the kit protocol except that the trypsin was diluted 1:6 with reagent $1 \mathrm{~B}$. Labeled and unlabeled cells were counted in 20 chondrocyte columns per animal in the central two thirds of the growth plate sections and averaged.

Microcomputed tomography (micro-CT). Excised and fixed femora from wild-type and p27 knockout mice were scanned using a MicroCAT II scanner (Imtek, Inc., Knoxville, TN). Each femur was immobilized on the sample table using plastic foam. The scanning conditions were as follows: resolution $50 \mu \mathrm{m}$, voxel size $30 \mu \mathrm{m}, 80 \mathrm{kVp}, 500 \mu \mathrm{A}$, and 720 projections over 360 degrees. After scanning, three-dimensional images of the whole femora were reconstructed and used to measure total length (most proximal to most distal point), shaft width (measured at mid-shaft), cortex width (measured at midshaft at $0,90,180$, and 270 degrees and averaged), bone volume, and bone mineral density. 
Statistics. Data were presented as mean \pm SEM. For the real-time PCR data, triplicate threshold cycle values were averaged and then the relative amounts of p27 mRNA were normalized to an endogenous control, 18S ribosomal RNA, in the same sample to account for variability in the initial concentration and quality of total RNA and in the efficiency of the reverse transcription reaction. This normalization was calculated as described by Pfaffl (23). To analyze differences between tissues, relative expression values were $\log$ transformed to achieve a normal distribution, and analyzed by ANOVA followed by Holm-Sidak comparisons between adjacent regions.

Phenotypic comparisons between wild-type and p27-deficient groups were made by two-way ANOVA with sex and genotype as independent variables. One mouse was eliminated from the micro-CT data because of a fractured femur. For the dexamethasone administration experiment, comparisons between wild-type and p27-deficient mice were made using a generalized linear model using three independent variables: genotype, sex, and treatment.

\section{RESULTS}

Expression of p27 mRNA in the growth plate and surrounding bone. In the wild-type mouse growth plate, p27 mRNA expression was assessed by real-time PCR. p27 mRNA was detected in both resting/proliferative zone and in hypertrophic zone at similar levels. However, the concentration of mRNA (normalized to 18S ribosomal RNA concentration in the same sample) in both regions of the growth plate was approximately 2 -fold lower than in the surrounding bone (Fig. 1). As a negative control we measured the expression of p27 mRNA in two p27-deficient mice. In both mice, the p27 mRNA expression was undetectable in growth plate and surrounding bone tissue. To confirm the accuracy of the dissection, we analyzed mRNA expression for type X collagen and type I collagen. As expected, type $\mathrm{X}$ collagen was primarily expressed in the hypertrophic cartilage and type I collagen was primarily expressed in the bone (Fig. 1).

Growth phenotype of p27-deficient mice. Ablation of p27 in mice had a mild positive effect on body size measured at 7 wk of age (Table 1, ANOVA using sex and genotype as independent variables). p2 $7^{-/-}$mice had an increased body weight compared with $\mathrm{p} 27^{+/+}$littermates. Weight of the spleen, heart, liver, and kidney were also significant increased in $\mathrm{p} 27^{-/-}$mice.
Ablation of p27 increased the body length, suggesting greater longitudinal growth of the vertebrae, but did not significantly affect the length of the tibia or femur. Width of the femur mid-shaft was significantly increased in $\mathrm{p} 27^{-/}$ compared with wild-type mice (Table 1). This increase in shaft width did not result in an increase in mid-shaft cortical thickness or in overall femoral bone density, measured by micro-CT scan.

Growth plate morphology and proliferation in p27deficient mice. p27 deficiency had no discernable effect on tibial growth plate morphology (Fig. 2). Total growth plate width, the number of proliferative and hypertrophic cells per intact column, and the height of the terminal hypertrophic cell did not differ significantly between p27-deficient and wildtype mice (Table 2). However, growth plate chondrocyte proliferation, assessed by BrdU-labeling index, was greater in p27-deficient than in wild-type mice (Table 2).

Dexamethasone-induced growth inhibition in p27deficient mice. Treatment of 3-wk-old mice with dexamethasone for $4 \mathrm{wk}$ caused a significant decrease in total body weight, tibial length, and femoral length but not in body length when compared with untreated controls (Table 3). This decrease was observed in both wild-type and p27-deficient mice. The magnitude of this growth inhibition did not significantly differ with the genotype ( $p=$ NS for body weight, tibial length, and femoral length, and body length). Therefore dexamethasone appeared to have a similar effect on wild-type and p27-deficient mice.

\section{DISCUSSION}

p27 mRNA was detected in the growth plates of 5-wk-old mice by real-time PCR. The p27 mRNA levels in growth plate were approximately 2 -fold lower than levels in the surrounding epiphyseal and metaphyseal bone tissue.

The expression of p27 mRNA was not significantly greater in the hypertrophic zone than in the resting/proliferative zone.
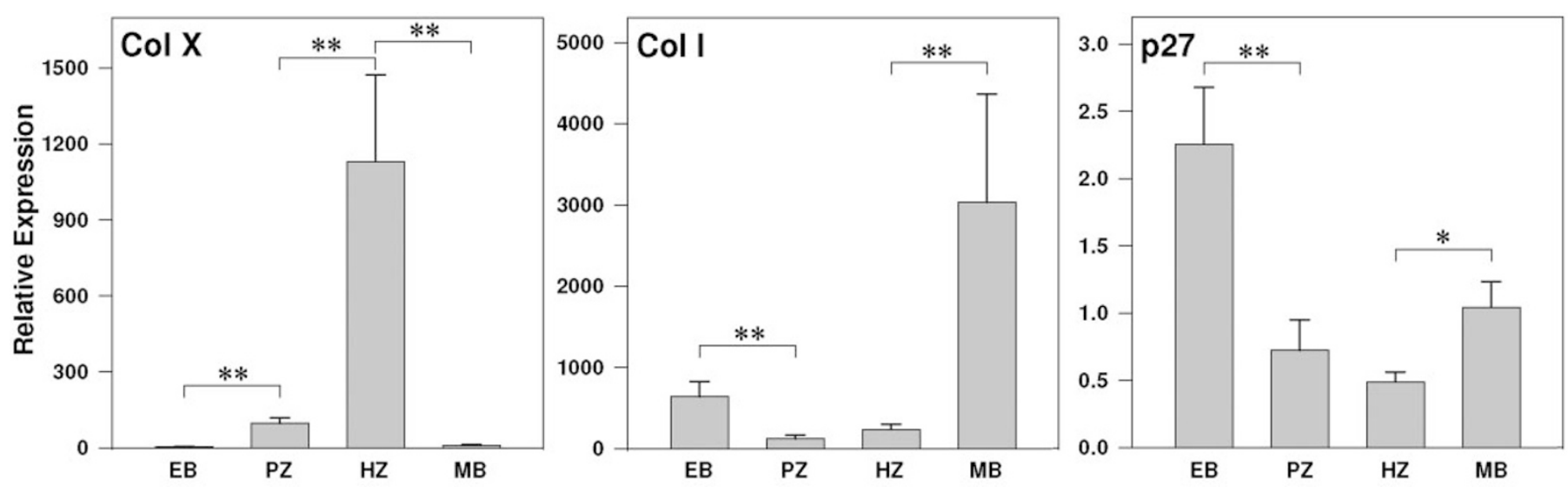

Figure 1. Relative mRNA expression (mean \pm SEM) of type X collagen, type I collagen, and p27 in proximal tibial growth plate and surrounding bone of 5-wk-old wild-type mice. Epiphyseal bone, resting plus proliferative zone, hypertrophic zone, and metaphyseal bone samples were isolated. For each zone of each animal, approximately 16 sections were pooled before RNA isolation and reverse transcription. mRNA expression was measured by real-time PCR using oligonucleotide primers and TaqMan probes. All samples were run in triplicate. The mRNA content of each gene was normalized to 18S ribosomal RNA content in the same sample and, for ease of comparison, multiplied by $10^{6}$. Statistical significance was assessed by ANOVA, followed by Holm-Sidak. **Significance of $<0.001$, *significance of 0.020 . Values shown are not corrected for multiple comparisons. 
Table 1. Body and organ size of wild-type and p27-deficient mice

\begin{tabular}{|c|c|c|c|c|c|c|c|c|c|}
\hline & \multicolumn{4}{|c|}{ Males } & \multicolumn{4}{|c|}{ Females } & \multirow{2}{*}{$\frac{\frac{\text { Both sexes }}{\mathrm{p} 27^{-/-} v s \mathrm{p} 27^{+/+}(\mathrm{ANOVA})}}{p \text { Value }}$} \\
\hline & Mean & SEM & Mean & SEM & Mean & SEM & Mean & SEM & \\
\hline Weight $(g)$ & 22.3 & \pm 0.465 & 26.6 & $\pm 1.087 * *$ & 19.4 & \pm 0.504 & 21.8 & $\pm 0.729 *$ & $<0.001$ \\
\hline Spleen weight $(\mathrm{g})$ & 0.063 & \pm 0.004 & 0.102 & $\pm 0.007 * *$ & 0.066 & \pm 0.006 & 0.083 & \pm 0.007 & $<0.001$ \\
\hline Heart weight $(\mathrm{g})$ & 0.148 & \pm 0.01 & 0.191 & $\pm 0.008 * *$ & 0.133 & \pm 0.006 & 0.141 & \pm 0.009 & 0.005 \\
\hline Body length without tail $(\mathrm{cm})$ & 9.3 & \pm 0.1 & 9.6 & \pm 0.1 & 9.0 & \pm 0.1 & 9.4 & $\pm 0.2^{*}$ & 0.003 \\
\hline Body length with tail $(\mathrm{cm})$ & 16.6 & \pm 0.1 & 17.1 & $\pm 0.1^{*}$ & 16.1 & \pm 0.1 & 16.3 & \pm 0.2 & 0.025 \\
\hline Tibia length $(\mathrm{mm})$ & 17.38 & \pm 0.19 & 17.51 & \pm 0.1 & 16.82 & \pm 0.21 & 17.05 & \pm 0.11 & NS \\
\hline Femur length (mm) & 14.49 & \pm 0.14 & 14.42 & \pm 0.12 & 13.85 & \pm 0.19 & 14.07 & \pm 0.13 & NS \\
\hline Femur shaft width (mm) & 1.62 & \pm 0.03 & 1.84 & $\pm 0.05^{* *}$ & 1.63 & \pm 0.02 & 1.79 & $\pm 0.05^{* *}$ & $<0.001$ \\
\hline Femur cortex width (mm) & 0.226 & \pm 0.011 & 0.254 & \pm 0.015 & 0.247 & \pm 0.007 & 0.251 & \pm 0.007 & NS \\
\hline
\end{tabular}

$* p<0.05, * * p<0.01$.

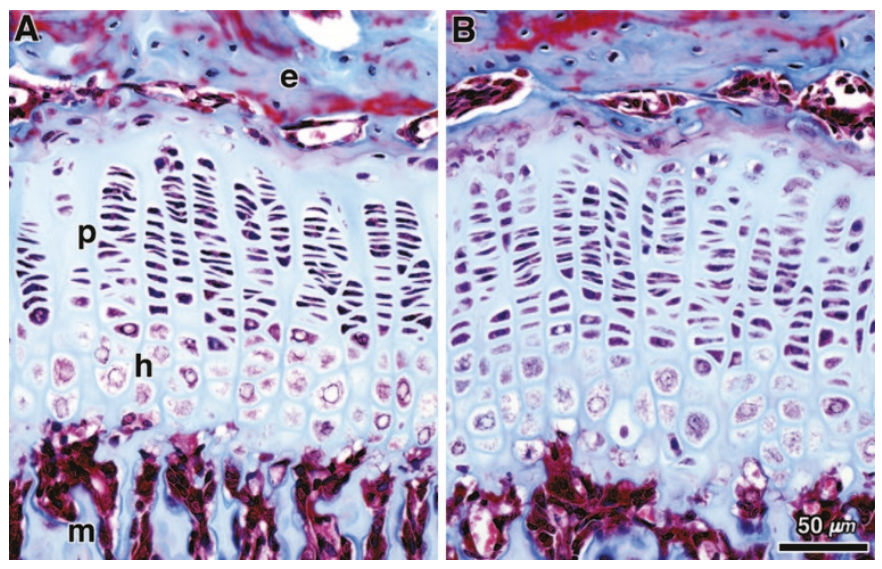

Figure 2. Representative photomicrographs of proximal tibial growth plates of $\mathrm{p} 27^{+/+}(A)$ and $\mathrm{p} 27^{-1-}(B)$ mice at $7 \mathrm{wk}$ of age. Longitudinal $5 \mu \mathrm{m}$ sections were obtained near the center of the formalin-fixed, decalcified bone and stained with Masson Trichrome. No differences were observed between the two genotypes. $e$, epiphyseal bone; $p$, proliferative zone; $h$, hypertrophic zone; $m$, metaphyseal bone.

This finding does not support the hypothesis that up-regulation of p27 is involved in terminal differentiation of growth plate chondrocytes $(13,14,24)$. Earlier studies using immunohistochemistry reported p27 expression primarily in hypertrophic chondrocytes of fetal mouse long bones. This divergence in results could be due to a difference between mRNA and protein expression, to developmental changes in p27 expression, or to the poor quantitative nature of immunohistochemistry $(15,16)$. The current study is the first to assess the expression of p27 in the growth plate using a quantitative method and the first to assess expression in the growth plate beyond the neonatal period.

In tissues from $\mathrm{p} 27^{-/-}$mice, we did not detect $\mathrm{p} 27$ expression, which indicates that our real-time PCR assay was specific for p27 mRNA. The observed p27 expression in the growth plate is unlikely to be due to contamination from the surrounding bone because measurement of type I and type X collagen mRNA levels suggests that the microdissection was quite accurate. The surrounding bone tissue consists of several different cell types, and this study does not determine the level of p27 expression in different bone cells.

To determine whether the p27 expression in the growth plate is physiologically important, we studied skeletal growth in p27-deficient mice. p27-deficient mice had a slightly greater body length than wild-type mice, presumably reflecting greater growth of the vertebrae. In long bones, p27 ablation was associated with a modestly increased rate of chondrocyte proliferation. The tibial and femoral lengths were not significantly different from those of wild-type littermates, suggesting that the increase in growth plate chondrocyte proliferation had begun shortly before $7 \mathrm{wk}$ of age, the time when the differences in body size are beginning to manifest $(17,20)$. Alternatively, the lack of difference in bone length despite an increase in growth plate chondrocyte proliferation might reflect a decrease in matrix production rate or an increase in apoptosis of nonterminal chondrocytes. Taken together, our findings indicate that p27 has a mild inhibitory effect on the normal proliferation of proliferative zone chondrocytes. Kiyokawa et al. (17) also mentioned a positive effect of p27 ablation on bone length in mice although the actual bone length was not presented in that paper. The magnitude of the effect on skeletal growth in different studies may depend on genetic background. Previous studies in other backgrounds (coisogenic 129S4 mice) show an approximately 30\% greater weight in p27-deficient than wild-type mice $(10,14,17)$, whereas we observed only a $19 \%$ (male) and $13 \%$ (female) difference at $7 \mathrm{wk}$ of age. Nonetheless, the small magnitude of the effect suggests that p27 is not necessary for the normal growth deceleration that occurs with age. The absence of skeletal growth deceleration would allow continued growth at fetal rates, which would be expected to have yielded a dramatic increase in bone length.

There was no discernable effect of p27 deficiency on growth plate morphology. In particular, the number of proliferative chondrocytes and the number of hypertrophic chondrocytes per column were unaffected. One previous study mentioned that the overall growth plate height was unaffected by p 27 ablation but that the proliferative zone of $\mathrm{p} 27^{-/-}$mice appeared larger in some sections. However, in that study, no supporting 
Table 2. Growth plate characteristics of wild-type versus p27-deficient mice

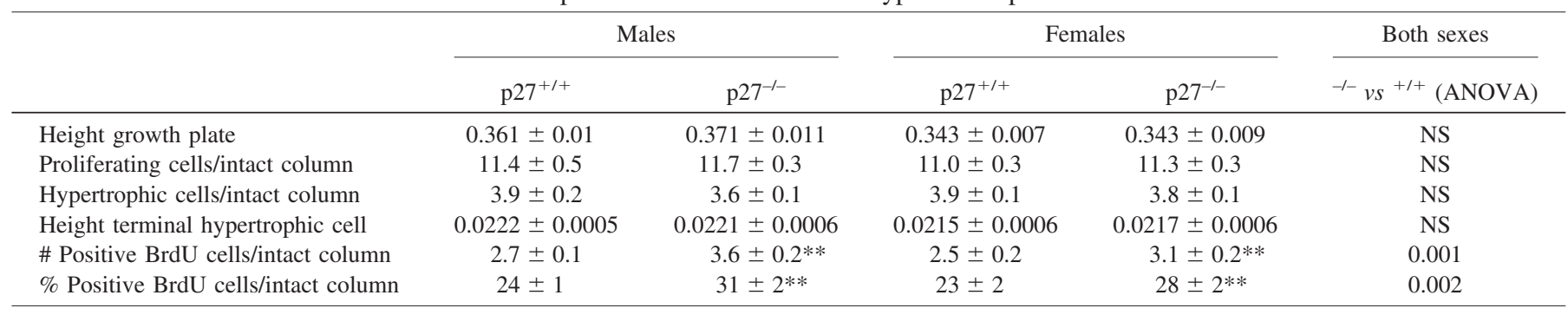

$* * p<0.01$

Table 3. Effect of dexamethasone treatment on body and bone growth in wild-type and p27-deficient mice

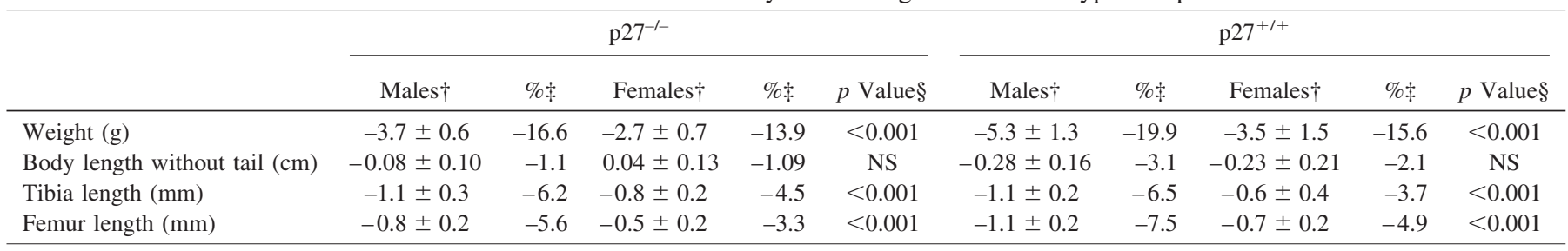

$\dagger$ Dexamethasone-treated minus untreated controls (mean \pm SEM).

$\ddagger \%$ change $=100 *$ (dexamethasone-treated minus untreated controls)/untreated controls.

$\S$ Dexamethasone-treated vs untreated controls (males and females combined).

quantitative data were reported (14). The BrdU-labeling index was increased in the proliferative zone of $\mathrm{p} 27^{-/}$compared with $\mathrm{p} 27^{+/+}$mice, whereas the number of chondrocytes in the proliferative zone was the same in $\mathrm{p} 27^{-/-}$and $\mathrm{p} 27^{+/+}$mice. This difference may occur because the number of proliferative chondrocytes depends not only on the number of cells being generated per column but also on how far down the column the cells undergo terminal differentiation into hypertrophic chondrocytes. Therefore, it is possible to have an effect on proliferation rate and not on number of proliferative chondrocytes. Our findings indicate that p27 is not necessary for the cessation in proliferation and for the terminal differentiation that occurs near the boundary between the proliferative and hypertrophic zones. Thus, p27 is not critical for the spatial regulation of growth plate chondrocyte proliferation.

We next hypothesized that $\mathrm{p} 27$ might mediate the growthsuppressing effects of glucocorticoids and thus play an important role in the conditional regulation of growth plate chondrocyte proliferation. The growth-inhibiting effects of glucocorticoids are the result of a decrease in proliferation and possibly an increase in apoptosis (25). The growth-inhibiting effects of glucocorticoids in other cell types may be mediated in part by p27 (26). Thus, p27-deficient murine embryonic fibroblasts are partially resistant to the growth-inhibitory effects of glucocorticoids (27). However, in our experiment, dexamethasone administration slowed longitudinal bone growth in p27-deficient mice and wild-type mice to a similar extent. Thus, p27 does not appear to be necessary for the decreased proliferation of growth plate chondrocytes induced by excess glucocorticoid in mice.

p27 affected not only the process of longitudinal bone growth but also radial growth of the diaphyseal cortex. p2 $7^{-/-}$ mice showed a greater diaphyseal width of the femur. This finding is consistent with a previous report (14). In contrast to the overall shaft width, we found that the cortical thickness (from endosteal to periosteal surface) was not increased.
Similarly, overall femoral bone density, which is highly dependent on cortical thickness, was not affected by p27 ablation. Taken together, these data suggest that periosteal bone growth is increased in the absence of p27, but that endosteal resorption may also be increased, thus negating any effect on cortical thickness. The increase in diaphyseal width might be caused by increased mechanical load due to increased body weight or to a direct effect of p27 on periosteal growth.

We chose to study the role of p27 in the regulation of longitudinal growth because of the suggestion from previous studies $(13,14)$ that it may regulate growth plate chondrocyte proliferation and differentiation. Other cell cycle regulators may also be important in the regulation of longitudinal growth. For example, mice lacking p57 have altered cell proliferation and differentiation, leading to endochondral bone ossification defects with incomplete differentiation of hypertrophic chondrocytes (28). Also, p21 ${ }^{\mathrm{CIP} 1 / \mathrm{WAF} 1}$ might play a role in skeletal growth since it is shown to be expressed in both the proliferative and hypertrophic zones in the growth plate of mice, rats, and pigs $(29,30)$.

In conclusion, our findings suggest that $\mathrm{p} 27$ is expressed in the growth plate. p27 ablation modestly increases growth plate chondrocyte proliferation, the process of longitudinal bone growth, and periosteal bone growth. However, p27 does not appear to be required for the inhibition of chondrocyte proliferation that occurs during hypertrophic differentiation, with increasing age, or in response to glucocorticoid excess. Thus, our findings suggest that p27 negatively modulates growth plate chondrocyte proliferation, but it is not required for spatial, temporal, or conditional regulation of chondrocyte proliferation in the growth plate.

\section{REFERENCES}

1. Kember NF, Walker KV 1971 Control of bone growth in rats. Nature 229:428-429

2. Aizawa T, Kokubun S, Tanaka Y 1997 Apoptosis and proliferation of growth plate chondrocytes in rabbits. J Bone Joint Surg Br 79:483-486 
3. Farquharson C, Loveridge N 1990 Cell proliferation within the growth plate of long bones assessed by bromodeoxyuridine uptake and its relationship to glucose 6-phosphate dehydrogenase activity. Bone Miner 10:121-130

4. Hunziker EB, Schenk RK 1989 Physiological mechanisms adopted by chondrocytes in regulating longitudinal bone growth in rats. J Physiol 414:55-71

5. Weise M, De Levi S, Barnes KM, Gafni RI, Abad V, Baron J 2001 Effects of estrogen on growth plate senescence and epiphyseal fusion. Proc Natl Acad Sci U S A 98:6871-6876

6. van der Eerden BC, Karperien M, Gevers EF, Lowik CW, Wit JM 2000 Expression of Indian hedgehog, parathyroid hormone-related protein, and their receptors in the postnatal growth plate of the rat: evidence for a locally acting growth restraining feedback loop after birth. J Bone Miner Res 15:1045-1055

7. van der Eerden BC, Karperien M, Wit JM 2003 Systemic and local regulation of the growth plate. Endocr Rev 24:782-801

8. Johnson DG, Walker CL 1999 Cyclins and cell cycle checkpoints. Annu Rev Pharmacol Toxicol 39:295-312

9. Gartel AL, Serfas MS, Tyner AL 1996 p21-negative regulator of the cell cycle. Proc Soc Exp Biol Med 213:138-149

10. Fero ML, Rivkin M, Tasch M, Porter P, Carow CE, Firpo E, Polyak K, Tsai LH, Broudy V, Perlmutter RM, Kaushansky K, Roberts JM 1996 A syndrome of multiorgan hyperplasia with features of gigantism, tumorigenesis, and female sterility in p27(Kip1)-deficient mice. Cell 85:733-744

11. Kato JY, Matsuoka M, Polyak K, Massague J, Sherr CJ 1994 Cyclic AMP-induced G1 phase arrest mediated by an inhibitor (p27Kip1) of cyclin-dependent kinase 4 activation. Cell 79:487-496

12. Nourse J, Firpo E, Flanagan WM, Coats S, Polyak K, Lee MH, Massague J, Crabtree GR, Roberts JM 1994 Interleukin-2-mediated elimination of the p27Kip1 cyclindependent kinase inhibitor prevented by rapamycin. Nature 372:570-573

13. Ballock RT, Zhou X, Mink LM, Chen DH, Mita BC, Stewart MC 2000 Expression of cyclin-dependent kinase inhibitors in epiphyseal chondrocytes induced to terminally differentiate with thyroid hormone. Endocrinology 141:4552-4557

14. Drissi H, Hushka D, Aslam F, Nguyen Q, Buffone E, Koff A, van Wijnen A, Lian JB, Stein JL, Stein GS 1999 The cell cycle regulator p27kip1 contributes to growth and differentiation of osteoblasts. Cancer Res 59:3705-3711

15. Horner A, Shum L, Ayres JA, Nonaka K, Nuckolls GH 2002 Fibroblast growth factor signaling regulates Dach1 expression during skeletal development. Dev Dyn 225:35-45

16. Sunters A, McCluskey J, Grigoriadis AE 1998 Control of cell cycle gene expression in bone development and during c-Fos-induced osteosarcoma formation. Dev Genet 22:386-397

17. Kiyokawa H, Kineman RD, Manova-Todorova KO, Soares VC, Hoffman ES, Ono M, Khanam D, Hayday AC, Frohman LA, Koff A 1996 Enhanced growth of mice lacking the cyclin-dependent kinase inhibitor function of p27(Kip1). Cell 85:721732

18. Nagahama H, Hatakeyama S, Nakayama K, Nagata M, Tomita K, Nakayama K 2001 Spatial and temporal expression patterns of the cyclin-dependent kinase (CDK) inhibitors p27Kip1 and p57Kip2 during mouse development. Anat Embryol (Berl) 203:77-87

19. Teixeira LT, Kiyokawa H, Peng XD, Christov KT, Frohman LA, Kineman RD 2000 p27Kip1-deficient mice exhibit accelerated growth hormone-releasing hormone (GHRH)-induced somatotrope proliferation and adenoma formation. Oncogene 19:1875-1884

20. Lin J, Della-Fera MA, Li C, Page K, Choi YH, Hartzell DL, Baile CA 2003 P27 knockout mice: reduced myostatin in muscle and altered adipogenesis. Biochem Biophys Res Commun 300:938-942

21. Hughes PC, Tanner JM 1970 A longitudinal study of the growth of the black-hooded rat: methods of measurement and rates of growth for skull, limbs, pelvis, nose-rump and tail lengths. J Anat 106:349-370

22. Heinrichs C, Yanovski JA, Roth AH, Yu YM, Domene HM, Yano K, Cutler GB Jr, Baron J 1994 Dexamethasone increases growth hormone receptor messenger ribonucleic acid levels in liver and growth plate. Endocrinology 135:1113-1118

23. Pfaffl MW 2001 A new mathematical model for relative quantification in real-time RT-PCR. Nucleic Acids Res 29:e45-

24. Beier F, Taylor AC, LuValle P 1999 The Raf-1/MEK/ERK pathway regulates the expression of the p21(Cip1/Waf1) gene in chondrocytes. J Biol Chem 274:3027330279

25. Smink JJ, Gresnigt MG, Hamers N, Koedam JA, Berger R, Buul-Offers SC 2003 Short-term glucocorticoid treatment of prepubertal mice decreases growth and IGF-I expression in the growth plate. J Endocrinol 177:381-388

26. Rogatsky I, Hittelman AB, Pearce D, Garabedian MJ 1999 Distinct glucocorticoid receptor transcriptional regulatory surfaces mediate the cytotoxic and cytostatic effects of glucocorticoids. Mol Cell Biol 19:5036-5049

27. Wang Z, Garabedian MJ 2003 Modulation of glucocorticoid receptor transcriptiona activation, phosphorylation, and growth inhibition by p27Kip1. J Biol Chem 278:50897-50901

28. Zhang P, Liegeois NJ, Wong C, Finegold M, Hou H, Thompson JC, Silverman A, Harper JW, DePinho RA, Elledge SJ 1997 Altered cell differentiation and proliferation in mice lacking p57KIP2 indicates a role in Beckwith-Wiedemann syndrome. Nature 387:151-158

29. Stewart MC, Farnum CE, MacLeod JN 1997 Expression of p21CIP1/WAF1 in chondrocytes. Calcif Tissue Int 61:199-204

30. Zenmyo M, Komiya S, Hamada T, Hiraoka K, Suzuki R, Inoue A 2000 p21 and parathyroid hormone-related peptide in the growth plate. Calcif Tissue Int 67:378381 